\title{
Helping refugees build new lives: from consultation to collaboration
}

\author{
Peter Shergolda,b
}

${ }^{a}$ NSW Department of Premier and Cabinet, Social Policy Group, Sydney, Australia

b Corresponding author: p.shergold@westernsydney.edu.au

\section{Article history}

Publication date: March 2018

Citation: Shergold P. Helping refugees build new lives: from consultation to collaboration. Public Health Res Pract. 2018;28(1):e2811801. https://doi. org/10.17061/phrp2811801

\section{Key points}

\section{- Cross-sector collaboration requires a shared common purpose, and its longevity depends on embedding a culture of collaboration in governance structures}

- By testing and refining ideas with the notfor-profit sector and refugees themselves, we've created new programs designed around the needs of the client, not traditional agency lines

- The Refugee Employment Support Program leverages the expertise of the community, education and private sectors to create employment pathways and support the long-term wellbeing of refugees

\begin{abstract}
Professor Peter Shergold was appointed as the New South Wales (NSW) Coordinator General for Refugee Resettlement in 2015, providing him with an opportunity to reimagine how the not-for-profit, public and private sectors could collaborate to improve the wellbeing of refugees settling in NSW, Australia. Through collaboration, NSW agencies are shifting the service response from one that is reactive to refugees' immediate settlement needs towards an investment approach that creates employment pathways. By identifying and building on refugees' strengths, resilience and human capital, Professor Shergold believes NSW can deliver better outcomes for both refugees and the communities they live in. PHRP asked him about his role, its objectives and its achievements.
\end{abstract}

\section{Interview}

Q: Tell us about the establishment of your role as New South Wales (NSW) Coordinator General for Refugees, and its objectives.

A: I was appointed by the NSW Premier as NSW Coordinator General for Refugee Resettlement in September 2015. My role was to ensure NSW was prepared for the arrival of an additional intake of refugees fleeing the humanitarian crisis in Syria and Iraq.

Refugees arriving in Australia come from highly diverse backgrounds and experiences, and as a result face a range of different challenges throughout their settlement journey. The complexity of these challenges, like so many other social policy issues, means that not one level of government, individual organisation or sector can solve them alone.

Being appointed to the role of Coordinator General presented me with an opportunity to think differently about how to best support refugees settling in NSW. Although it was important to ensure that state government agencies took a coordinated whole-of-government approach, and liaised effectively with the Australian Government, I saw myself as having a far broader ambit. Here, I thought, was a chance to reimagine governance - to explore 
opportunities to collaborate not only with different levels of government but across sectors. From the outset, I have been committed to working in true partnership with the nongovernment, community, corporate and education sectors, and to moving the relationship between the public service and these organisations from consultation to collaboration and, even, to coproduction.

$\mathbf{Q}$ : What in your view are the most important elements of successful collaboration?

A: I am a firm believer in the potential of deeper collaboration across sectors to deliver better outcomes, but I am also well aware that true collaboration involves particular challenges. In my experience, there are several critical elements that underpin successful collaborative partnerships. My experience working with the community sectors in Western Australia and Victoria had persuaded me that if not-for-profits and businesses were going to work together with the public sector, there needs to be "an appreciation of the constraints under which all sides operate, mutual respect, reciprocated trust, authentic consultation and a shared recognition of common purpose". 1

With this in mind, I established the Joint Partnership Working Group (JPWG) on refugee resettlement. The group comprises senior leaders from both government and nongovernment organisations, including humanitarian settlement service providers. My sense is that, as a group, we have built a strong relationship based on a shared common purpose to improve the wellbeing of refugees arriving in NSW. Importantly, establishing this group has embedded collaboration as a core principle underpinning a new approach to refugee settlement in NSW. Too often I have seen excellent collaborative partnerships falter when leadership 'heroes' move on to different organisations. Somehow the culture of collaboration must be embedded into governance structures to ensure its longevity. That's tough: it's much easier to reorganise organisational structures than to change minds.

Q: Do you think the NSW collaborative model has the necessary structure and governance to ensure its success?

A: I am cautiously optimistic that it can be done. Certainly, my experience with the JPWG has reconfirmed my earlier conclusion that "contracted organisations can add significant value to consideration of the structures by which government payments and services are delivered". ${ }^{2}$ I believe the results speak for themselves.

Together, the NSW public and community sectors developed new proposals to strengthen the service system for refugees across a range of areas, including youth, community engagement, and health and education support. These ideas were then tested and refined at a workshop with 100 representatives from approximately 60 community organisations to ensure they reflected the valuable insights of frontline community workers. We also held multiple roundtables to focus in on particular sector's views, including education, local government and volunteers. This was a relatively intense process of evaluating what worked, how outcomes could be improved and what gaps remained. As a result, existing services are being expanded to meet increased demand and new initiatives are being developed to leverage connections across service providers and sectors. Community organisations significantly influenced the NSW Budget bid that went forward. As a consequence, we were successful in securing an additional \$146 million in funding over 4 years from the NSW Government. The NSW Department of Industry then allocated a further $\$ 25$ million to fund additional refugee employment initiatives over the same period.

$\mathbf{Q}$ : Can you give an example of cross-sector collaboration in action?

A: The Service for the Treatment and Rehabilitation of Torture and Trauma Survivors (STARTTS) School Liaison Program is a prime example of how collaboration across sectors can produce better outcomes for both refugees and those working in the service system. This new program was designed to make specialist torture and trauma services more available to students in government and nongovernment schools, and build the capacity of schools to respond to the needs of these students. By designing services around the needs of the client, rather than demarcating programs along traditional agency lines, we could improve the wellbeing of refugee students and make more effective use of resources. This wouldn't have been possible without a robust relationship between STARTTS, NSW Health and the NSW Department of Education. They are to be commended on their commitment to develop flexible and innovative responses to challenging issues. They recognise that the goal is not just to remove wasteful duplication of services but to leverage their respective contributions through collaboration. The sum is greater than the parts.

Cross-sector collaboration also allows us to discover current gaps in the service system that may otherwise have gone unnoticed by government agencies working alone, while exploring new ways of designing and delivering services. As a case in point, the JPWG identified a need for a specific initiative to support refugee youth, a potentially vulnerable cohort who greatly benefit from early engagement and support. At a roundtable meeting with a range of community-based youth organisations, it was agreed that codesigning a youth peer-mentoring program for refugees would meet an identified need. Most importantly, it would ensure that the end product reflected the views of refugee youth themselves. By genuinely listening to service providers and community members, we are creating a new program 
that will address a previously unmet need and places refugee youth at the core of its design and delivery.

Q: What are some of the priority areas for collaboration in refugee settlement?

A: Although settlement services are essential to ensure refugees have appropriate health, housing and education support, particularly during the first 12 months after arrival, there is significant evidence that "employment provides the bedrock for successful settlement". 3,4

We know that refugees make important contributions to the economy, through both their participation in the labour market and their role as small-scale entrepreneurs. However, it became clear during my conversations with refugees, service providers, community members and private sector employers that significantly more can be done to support refugees to pursue meaningful employment pathways. They need to aspire to jobs that are commensurate with their education, skill level and business ambition. Recent evidence published by the Centre for Policy Development supports this conclusion. Overall, only $17 \%$ of refugees are in paid work after being in Australia for 18 months, and many, particularly women, accept work that is below the skill level of positions previously held in their former country of residence. ${ }^{4}$

There is a clear opportunity for both the public and private sectors to better support refugees to find employment sooner after arrival, ideally at a level that reflects their education and experience. For this reason, I have made employment, education and training a primary focus of my work as Coordinator General. My aim has been to shift the NSW service response to refugees from one that is reactive to their immediate settlement needs to an investment approach that identifies and builds on the human capital they bring - their workforce experience, skills, qualifications and entrepreneurial drive.

I have been delighted with the corporate sector's response to this challenge. An increasing number of business organisations have committed to train, mentor or employ refugees. Many have also pledged to develop targeted refugee employment programs, provide employment grants and assist refugees to become 'job ready'. The private sector's support is critical to providing newly arrived refugees with better pathways to employment; however, they cannot be expected to tackle this challenge alone.

Q: Considering the above, can you provide an example of a successful program coordinated through your office that builds on the human capital of refugees?

A: We developed the \$22 million Refugee Employment Support Program. It will provide tailored support to up to 7000 refugees, including 1000 asylum seekers, in Western Sydney and the Illawarra. Organisations are contracted to develop individual career plans for refugees and link them to the appropriate education, training and employment pathways, including targeted programs and grants developed by the corporate sector. The program has been developed in partnership with refugee service providers, NSW Government agencies and corporate partners. It will be evaluated based not on process but on its impact on refugee employment outcomes. It is complemented by a NSW-based overseas skills recognition and advisory service, and an extension of fee-free training up to Certificate IV to all temporary and permanent humanitarian visa holders. The support of the NSW business and community sector has been matched by a commitment from the NSW Government to employ 100 refugees in the NSW public sector. For many, this will provide a stepping stone to broader employment opportunities.

The Refugee Employment Support Program provides an excellent demonstration of what can be achieved when the public, private and not-for-profit sectors work together, question how things are currently being done and strive together to create something better. It has been designed to enable each sector to focus on its area of expertise - ranging from tailored case management support, education and training, or job creation - and brings each of these elements together to deliver a better outcome for refugees and, ultimately, the communities they live in.

The capacity to help desperate refugees to build self-reliant lives for their families in a new country has its intrinsic satisfaction. To find new forms of collaborative governance to design, deliver and evaluate programs and services adds purpose to the exercise. What we learn in helping to achieve better outcomes for refugees can be applied in many other areas of government policy. 


\section{Acknowledgements}

The interview was conducted by the then Editor of Public

Health Research \& Practice, Anne Messenger.

\section{Competing Interests}

None declared

\section{References}

1. Shergold P. Service sector reform: a roadmap for community and human services reform. Melbourne: Victorian Government; 2013 [cited 2018 Feb 2]. Available from: vcoss.org.au/documents/2013/07/FINAL-ReportService-Sector-Reform.pdf

2. Shergold P. Three sectors, one public purpose. In: Butcher JR, Gilchrist DJ, editors. The three sector solution. Canberra: Australian National University Press; 2016. p. 23-32.

3. OECD. Making integration work: refugees and others in need of protection. Paris: OECD Publishing; 2016 [cited 2018 Feb 2]. p. 18. Available from: www.keepeek. com/Digital-Asset-Management/oecd/social-issuesmigration-health/making-integration-work-humanitarianmigrants_9789264251236-en\#.WnPiRaiWbIU\#page20

4. Centre for Policy Development. Settling better: reforming refugee employment and settlement services. Sydney: CPD; 2017 [cited 2018 Feb 1]. Available from: cpd.org. au/wp-content/uploads/2017/02/Settling-Better-Report20-February-2017.compressed.pdf

\section{Copyright: (c) (i) (2)}

(C) 2018 Shergold. This article is licensed under the Creative Commons Attribution-NonCommercial-ShareAlike 4.0 International Licence, which allows others to redistribute, adapt and share this work non-commercially provided they attribute the work and any adapted version of it is distributed under the same Creative Commons licence terms. See: www.creativecommons.org/licenses/by-nc-sa/4.0/ 